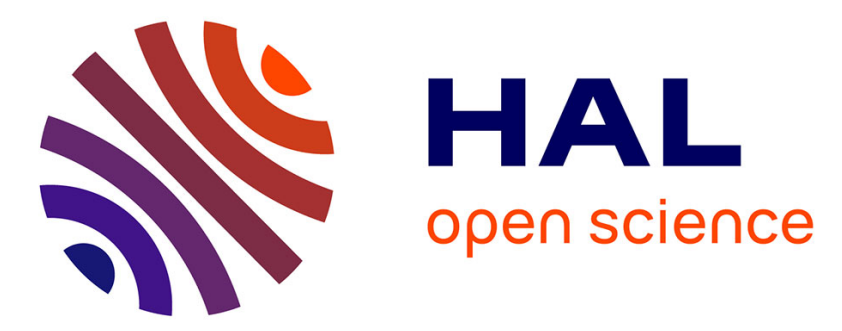

\title{
Infants' social evaluation abilities: testing their preference for prosocial agents at 6,12 and 18 months with different social scenarios
}

Claire Holvoet, Céline Scola, Thomas Arciszewski, Delphine Picard

\section{- To cite this version:}

Claire Holvoet, Céline Scola, Thomas Arciszewski, Delphine Picard. Infants' social evaluation abilities: testing their preference for prosocial agents at 6,12 and 18 months with different social scenarios. Early Child Development and Care, 2017, pp.1 - 14. 10.1080/03004430.2017.1361415 . hal-01763558

\section{HAL Id: hal-01763558 \\ https://hal.science/hal-01763558}

Submitted on 25 Apr 2018

HAL is a multi-disciplinary open access archive for the deposit and dissemination of scientific research documents, whether they are published or not. The documents may come from teaching and research institutions in France or abroad, or from public or private research centers.
L'archive ouverte pluridisciplinaire HAL, est destinée au dépôt et à la diffusion de documents scientifiques de niveau recherche, publiés ou non, émanant des établissements d'enseignement et de recherche français ou étrangers, des laboratoires publics ou privés. 


\title{
Infants' social evaluation abilities: Testing their preference for prosocial agents at 6,12 and 18 months old with different social scenarii
}

\author{
Holvoet, C., Scola, C., Arciszewski, T. \& Picard, D.
}

\begin{abstract}
A recent body of research suggests infants prefer prosocial behaviours. However, some studies failed to report this preference, and asked what specific parameters allow to observe it. We attempt to provide a part of answer to that question by investigating if the preference vary 1) with age (testing infants aged $6,12,18$ months), 2) with the type of social behaviours (help, play and share), and 3) when the pro- and antisocial agents' appearance were manipulated (i.e., displaying neutral, own-race or other-race faces). To this end, we use an eye-tracking methodology to assess infants' preference between pro- and antisocial agents featured in animated cartoons. We found that the prosocial preference was not stable across ages and varied depending on social scenarios. No sound conclusion could be given about the influence of faces. Our results invite to wonder in which extent very young infants perceive the prosociality in complex social behaviours.
\end{abstract}

\section{Introduction}

One key component of human's survival is his capacity to cooperate with social partners. Two kinds of social partners, however, have to been distinguished: those who cooperate, the "prosocial" ones, and those who do not, the "antisocial" ones. When this ability to identify the prosocial partners emerges in humans' life? This research question has animated a body of research since one decade. A variety of studies reported evidence that early in ontogeny - at the young age of 3 months - infants are able to distinguish between prosocial and antisocial characters (Hamlin, Wynn, \& Bloom, 2010), and that they then display a preference for prosocial ones (for a recent review, see Holvoet, Scola, Arciszewski \& Picard, 2016). When having to choose between two characters (puppets, wooden blocks or even cartoon characters), one that have behaved in a prosocial way and one in an antisocial way, infants in their first year of life displayed a spontaneous preference for the prosocial puppet. This preference has been replicated across different social scenario and experimental paradigms (see for example Buon et al., 2014; Geraci \& Surian, 2011; Scola, Holvoet, Arciszewski \& Picard, 2015). In addition to these first findings, it has been shown infants take into account agents' intentions as well as the social context in which the behaviour occurs (Hamlin, 2013; Hamlin, Ullman, Tenenbaum, Goodman \& Baker, 2013; Hamlin, Wynn, Bloom \& Mahajan, 2011). Moreover, neurodevelopmental research reported additional findings demonstrating infants discriminate prosocial from antisocial agents (for a review, see Decety \& Cowell, 2017). However, among the studies that have explored the emergence of these social evaluation abilities, some failed to observe such a preference for prosocial agents (Cowell \& Decety, 2015), and thus even if they carefully followed the precise methodology of Hamlin \& Wynn's (2011) study (Salvadori et al., 2015).

In these two studies, they presented to infants interactions involving puppets and movies of wooden blocks very similar - but not exactly the same - to those presented by Hamlin and colleagues (Hamlin, 2014; Hamlin \& Wynn, 2011; Hamlin et al., 2007), in the same social 
scenarios, but failed to observe a preference for the prosocial puppet in their three attempts. These failures raise question about the robustness of this preference as well as the potential influence of age (as Cowell \& Decety (2015) recruited infants aged 12-24 months whereas Hamlin and colleagues $(2007,2014)$ recruited infants aged between 6 and 10 months) on the one hand and of perceptual aspects/appearance on the other hand.

Regarding the influence of appearance, there are growing evidence that facial appearance quickly and unconsciously affects adult's assessment of social agents, inferring social dimensions on the basis of peoples' faces, as well as it affects their partner choice (Olivola, Funk \& Todorov, 2014; Stewart, Ajina, Getov, Bahrami, Todorov \& Rees, 2012; Todorov, Pakrashi \& Oosterhof, 2009). The same mechanism of characters-traits inferred from faces has been found in children (Cogsdill, Todorov, Spelke \& Banaji, 2014), and it can easily be assumed that appearance influence the way infants also assess and choose social partners as they early displayed perceptual preferences for example female over male faces (Quinn, Yahr, Kuhn, Slater \& Pascalis, 2002), or even own- versus other-race faces (Fassbender, Teubert, \& Lohaus, 2016; Liu et al., 2015).

To date, only few studies have explored the influence of appearance on infants' social evaluation and reported contrasted findings. A first study tested the influence of appearance by varying the race of the prosocial agent (Burns \& Sommerville, 2014). Namely, 15-monthold Caucasian infants were exposed to real life actors acting prosocially versus antisocially (i.e., distributing fairly or unfairly food to a third partner) and differing in race. When both actors were Caucasian, infants exhibit a spontaneous preference for the prosocial one. However, when the prosocial actor was Asian and the antisocial Caucasian, they did not prefer the prosocial actor suggesting infants' social evaluations are altered by modifications in facial appearance and specifically in race. However, another recent study (Scola, et al., 2015) found that Caucasian infants aged 12-36 months, exposed to an animated cartoon of a ball game involving a prosocial character (a game-player) versus an antisocial one (a gamebreaker), still preferred the prosocial character even when his face displayed changes (i.e., a dark skin).

Therefore, the studies that have explored so far the influence of appearance and specifically of race in infants' social evaluation reported different results. Again, it should be noted that they are many differences between these two studies: the age of infants tested (15 months in Burns \& Sommerville, 2014, and 12-36 months in Scola et al., 2015), the social scenarios (distribution of food in Burns and Sommerville, 2014, vs. a ball game in Scola et al., 2015), as well as the material used (real life actors in Burns and Sommerville, 2014, vs. animated cartoons in Scola et al., 2015). These are so many parameters that may have an impact on the results reported. More research testing simultaneously different social scenarios at different ages with the same methodology is needed to clearly identify the impact of race on infants' social evaluation and its potential variation with age and the kind of scenario. Moreover, we cannot ignore that in real life situations both components - behaviour and facial appearance are combined and it is thus important to determine the influence of facial appearance, through race information, on infants' preference for prosocial agents. The current study investigated this question by exposing infants to situations in which facial features and behaviour are in 
competition, to determine if they would display a preference for behaviour over facial features or the reverse.

Thus, we designed the present study from a threefold perspective. First, we tested whether the preference for prosocial behaviour varies with age by testing infants of 6,12 and 18 months. Second, we investigated whether the preference for prosocial behaviours varies depending on the kind of behaviour by exposing the infants to three different social scenarios ("Help", "Play", and "Share"). Last, we explored whether the preference for prosocial behaviour varies according to the appearance of the agents by exposing infants to the same social scenarios in which behaviours are in competition with facial characteristics (race).

More specifically, Caucasian infants aged 6,12 and 18 months watched animated cartoons that were designed to assess their visual preference i) between a prosocial versus an antisocial agent (condition A), ii) between an own-race (i.e., Caucasian) versus an other-race (i.e., African or Asian) agent (condition B), and when the prosocial agent's race vary, that-is-to-say : iii) between an own-race prosocial agent versus an other-race antisocial agent (condition $C$ ), and iv) between an other-race prosocial versus an own-race antisocial agent (condition D). These four conditions were depicted in three different scenarios called "Help", "Play", and "Share", where an "Helper", a "Game-player" and a "Sharer" were in competition with an "Hinderer", a "Game-breaker" and a "Keeper".

In condition A (prosocial condition), our prediction is that the preference for the prosocial behaviour would vary according to two factors: infants' age and the kind of scenario. Regarding age, we hypothesize that infants aged 6 and 12 months would show a preference for the prosocial over the antisocial agents as this preference has already been reported in previous research (Hamlin et al., 2007; Wallez, Scola, Holvoet \& Meunier, 2016). However, we cannot form any assumption about infants aged 18 months as this age range has never been observed before. Regarding the kind of scenario, we hypothesize that we would observe a preference for the prosocial behaviors in the Help and in the Play scenarios considering that previous work reported this preference in similar scenarios (see Hamlin et al., 2007, and Wallez et al., 2016, for similar scenarios to Help; and Hamlin \& Wynn, 2011, and Scola et al., 2015, for similar scenarios to Play). However, to our knowledge, this study is the first to show a social scenario that oppose a Sharer to a Keeper (i.e., previous studies that tested infants' understanding of sharing showed a fairly sharer and an unfairly one (Geraci \& Surian, 2011; Burns \& Sommerville, 2014) so that we cannot form any prediction regarding the Share scenario.

In condition B (face condition), we hypothesize infants would display a preference for the other-race agent over the own-race agent (preference for other-race with cartoon faces; prediction based on recent findings by Holvoet et al., submitted). Indeed, using a visual preference task, this study found infants prefer other-race face (vs. own-race) when faces are displayed in a cartoon (i.e., a basic drawing) format. Finally, in conditions $\mathrm{C}$ and $\mathrm{D}$ (combined conditions prosocial $x$ face), our assumptions are the following. If infants display a preference for behaviour over face, then they should preferentially look at the prosocial own-race agent in condition $\mathrm{C}$ and at the prosocial other-race agent in condition D. By contrast, if infants display a preference for face over behaviour, they should show a visual preference for the 
other-race antisocial agent in condition $\mathrm{C}$, and for the other-race prosocial agent in condition D. Finally, if both aspects (face and behaviour) are weighted equally by infants, it may be the case that no preference emerged in these combined conditions.

We decided to address these questions using an eye-tracking methodology. Commonly in this area of research, visual preferences have been measured through a classic visual preference task (i.e., when the two objects for which a preference is tested are presented static on a screen following a dynamic presentation; Hamlin \& Wynn, 2011; Hamlin, Wynn \& Bloom, 2010). However, eye-tracking technology, even if its use with young infants remains effortful and time taker (Oakes, 2012), presents the noticeable advantage to record infants' fixations during the dynamic presentation. Recent studies reported findings suggesting that, when assessing infants' visual preference between agents, the fixations recorded during the dynamic presentation (i.e., while the infants are watching the story unfold) were more sensitive compared with visual preferences observed with the classic preferential looking task (Cowell \& Decety, 2015; Wallez, Scola, Holvoet \& Meunier, 2016).

\section{Method}

\subsection{Participants}

A total of 236 infants participated in our study. Infants were distributed in three groups, one for each scenario ("Help", "Play", or "Share") as described below.

Seventy-one full-term and healthy infants were exposed to the "Help" scenario. Eleven were excluded from the analyses owing to fussiness $(<70 \%$ of time spent looking at the screen for the total duration of the experiment). In total, 20 6-month-olds (11 boys and 9 girls; Mean age $=6.36$ months, $S D=0.28$ months; age range $=5$ months 22 days to 6 months 18 days), 2012 month-olds (11 boys and 9 girls; Mean age $=12.58$ months, $S D=0.22$ months; age range = 11 months 24 days to 12 months 21 days), and 20 18-month-olds ( 8 boys and 12 girls; Mean age $=18.25$ months, $S D=0.23$ months; age range $=17$ months 18 days to 18 months 13 days), were included in the final sample.

Eighty-eight full-term and healthy infants were exposed to the "Play" scenario. Twenty-eight were excluded from the analyses owing to fussiness $(<70 \%$ of time spent looking at the screen for the total duration of the experiment). In total, 206 -month-olds (16 boys and 4 girls; Mean age $=6.18$ months, $S D=0.25$ months; age range $=5$ months 23 days to 6 months 18 days), 20 12-month-olds (11 boys and 9 girls; Mean age $=12.28$ months, $S D=0.44$ months; age range $=11$ months 10 days to 12 months 23 days), and 2018 -month-olds ( 14 boys and 6 girls; Mean age $=18.53$ months, $S D=0.30$ months; Age range $=17$ months, 26 days to 18 months, 26 days), were included in the final sample.

Seventy-seven full-term and healthy infants were exposed to the "Share" scenario. Seventeen were excluded from the analyses owing to fussiness $(<70 \%$ of time spent looking at the screen for the total duration of the experiment). In total, 206 -month-olds (10 boys and 10 girls; Mean age $=6.34$ months, $S D=0.28$ months; age range $=5$ months 22 days to 6 months 22 days), 20 12-month-olds (13 boys and 7 girls; Mean age $=12.53$ months, $S D=0.25$ months; age range $=11$ months 22 days to 12 months 21 days), and 2018 -month-olds ( 8 boys 
and 12 girls; Mean age $=18.30$ months, $S D=0.32$ months; age range $=17$ months 18 days to 18 months 21 days), were included in the final sample.

Parents gave a written informed consent for their child to participate. Infants were given a token gift for their participation. This study received the approval of the University's ethics committee $\left(\mathrm{n}^{\circ} 20150701001\right)$ and was conducted in accordance with the principles laid down by the Declaration of Helsinki, last version.

\subsection{Material}

The material consisted in 12 different color cartoons, four for each scenario, built with Adobe Flash. The four cartoons were used in four conditions (Conditions A, B, C and D) with a design principle that was the same for the three scenarios (Help, Play and Share). Each cartoon showed three human-like characters on a simple background, and came in two successive parts: a dynamic part (scenario), featuring moving characters; and a short static part (test phase). More specifically, the test phase began with the disappearance of the central character and the background, leaving two static, enlarged characters on the screen for 5 seconds. Conditions A and B were used to assess infants' preference for each component (i.e., behaviour, race) considered separately. Conditions $\mathrm{C}$ and $\mathrm{D}$ were designed as combined situations that featured the two components in competition. The four conditions are more specifically described hereinafter and illustrated in Figure 1, with the duration of the dynamic part of each cartoon specified in Table 1. Much description of the scenarios are available in the Supplementary Information.

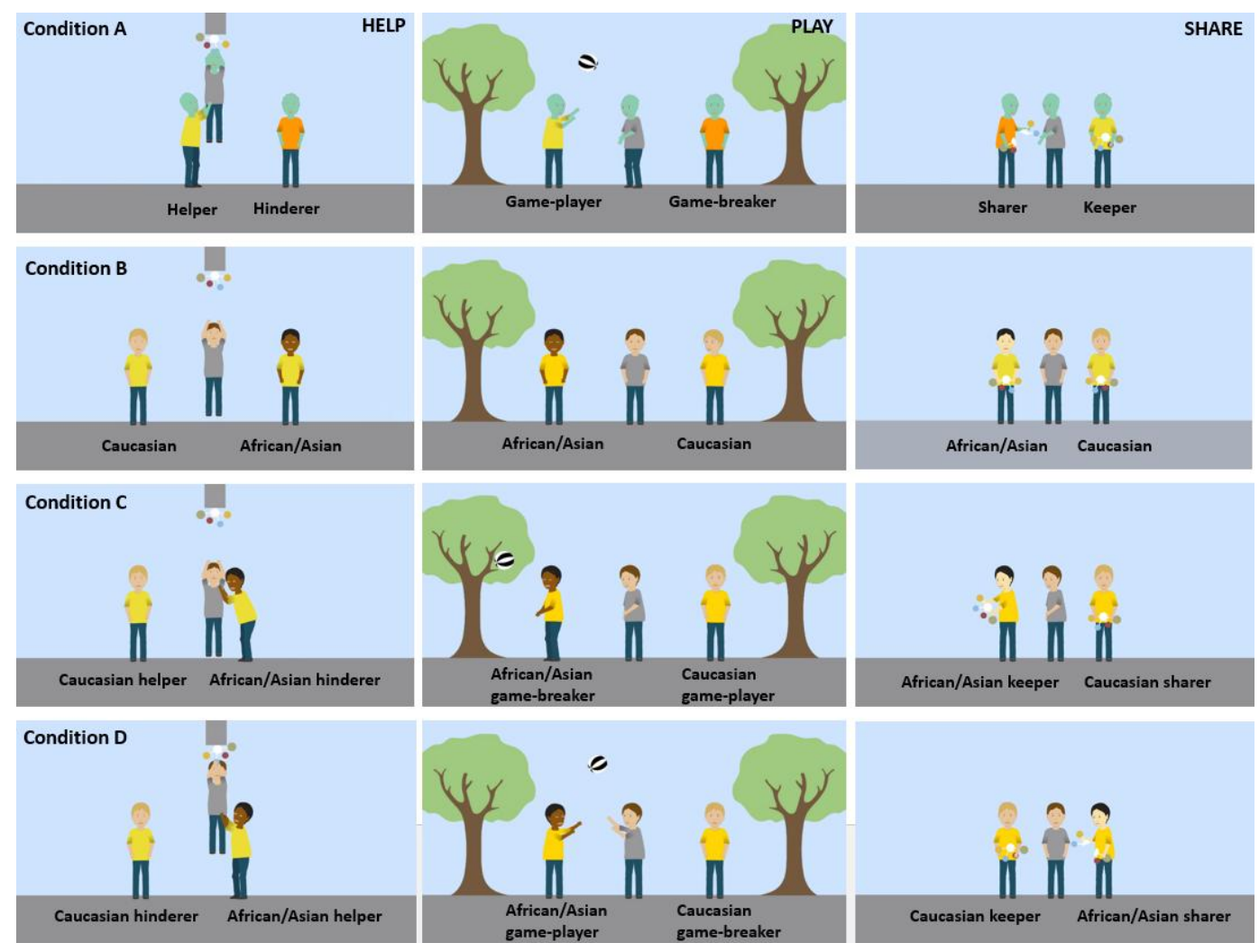

Figure 1. Illustration of the four conditions (A, B, C and D) used in each scenario (Help, Play, Share) with a description of each character. 
Table 1

Description of each characters included in the cartoon, the duration of the dynamic part and the signification of the IP according to scenario and condition

\begin{tabular}{|c|c|c|c|c|}
\hline & Help & Play & Share & IP \\
\hline Condition A & $\begin{array}{c}\text { Helper } v s \\
\text { Hinderer } \\
\text { (duration: } 35 \mathrm{~s} \text { ) }\end{array}$ & $\begin{array}{l}\text { Game-player } v s \\
\text { Game-breaker } \\
\text { (duration: } 40 \mathrm{~s} \text { ) }\end{array}$ & $\begin{array}{l}\text { Sharer vs Keeper } \\
\text { (duration: } 35 \mathrm{~s} \text { ) }\end{array}$ & $\begin{array}{c}>0.5 \text { : preference } \\
\text { prosocial }\end{array}$ \\
\hline Condition B & $\begin{array}{l}\text { Caucasian vs } \\
\text { African/Asian } \\
\text { (duration: } 8 \mathrm{~s} \text { ) }\end{array}$ & $\begin{array}{l}\text { Caucasian vs } \\
\text { African/Asian } \\
\text { (duration: } 20 \mathrm{~s} \text { ) }\end{array}$ & $\begin{array}{l}\text { Caucasian vs } \\
\text { African/Asian } \\
\text { (duration: } 10 \mathrm{~s} \text { ) }\end{array}$ & $\begin{array}{c}>0.5: \text { preference } \\
\text { own-race }\end{array}$ \\
\hline Condition $\mathrm{C}$ & $\begin{array}{c}\text { Caucasian } \\
\text { helper } v s \\
\text { African/Asian } \\
\text { hinderer } \\
\text { (duration: } 35 \mathrm{~s} \text { ) }\end{array}$ & $\begin{array}{c}\text { Caucasian game- } \\
\text { player } v s \\
\text { African/Asian game- } \\
\text { breaker } \\
\text { (duration: } 40 \mathrm{~s} \text { ) }\end{array}$ & $\begin{array}{c}\text { Caucasian sharer } \\
\text { vs African/Asian } \\
\text { Keeper } \\
\text { (duration: } 35 \mathrm{~s} \text { ) }\end{array}$ & $\begin{array}{c}>0.5 \text { : preference } \\
\text { own-race } \\
\text { prosocial }\end{array}$ \\
\hline Condition D & $\begin{array}{l}\text { African/Asian } \\
\text { helper } v s \\
\text { Caucasian } \\
\text { hinderer } \\
\text { (duration: } 35 \mathrm{~s} \text { ) }\end{array}$ & $\begin{array}{l}\text { African/Asian game- } \\
\text { player vs Caucasian } \\
\text { game-breaker } \\
\text { (duration: } 40 \mathrm{~s} \text { ) }\end{array}$ & $\begin{array}{l}\text { African/Asian } \\
\text { sharer } v s \\
\text { Caucasian } \\
\text { keeper } \\
\text { (duration: } 35 \mathrm{~s} \text { ) }\end{array}$ & $\begin{array}{c}>0.5 \text { : preference } \\
\text { other-race } \\
\text { prosocial }\end{array}$ \\
\hline
\end{tabular}

\section{Condition A (prosocial)}

The three cartoons used in Condition A were used to assess infants' preference for the prosocial (vs. antisocial) agent. In these cartoons, the characters had green faces, like "aliens", but normal facial features (cf Figure 1). In order to test infants' preference for prosociality in Condition A, we designed Aliens faces so that the characters all had the same "neutral" faces, and differed solely with respect to their prosocial or antisocial behaviour regarding the central character. Moreover, we wanted to avoid exposing infants to either own- or other-race faces. In each scenario, the central character had a specific wish or aim, and alternatively interacted with the characters on his right and on his left who behave either in a prosocial or antisocial way depending on the scenario. In the Help scenario, the central character repeatedly attempted to reach the toy placed above him. The prosocial character (the "Helper") came and raised him so that he could reach the toy, whereas the antisocial character (the "Hinderer") came and prevented him from jumping toward it. In the Play scenario, the central character threw the ball to the other characters to play with them. The prosocial character (the "Gameplayer") gave the ball back so that the game could continue, whereas the antisocial character (the "Game-breaker") kicked the ball in a three placed next to him. Finally, in the Share scenario, the two surrounding characters hold a toy in their hands and the central character alternatively asked for having the toy. The prosocial character (the "Sharer") cuts his toy in 
two pieces and gives it to the central character, whereas the antisocial one (the "Keeper") turns his back so that the he puts the toy out of his reach.

\section{Condition B (face)}

The three cartoons used in Condition B were used to assess infants' preference for the character who displays an own- or other-race face. In the three scenarios, these cartoons showed three characters: one in the middle of the screen and one on either side. The two characters surrounding the central character simply turned their faces towards the central character to look at him, and did not display any behaviour towards the latter that could be interpreted as being either pro- or antisocial. One of these two moving characters had an ownrace face (Caucasian), while the other had an other-race face (African or Asian).

\section{Condition C (prosocial $x$ face)}

The three cartoons used in Condition $\mathrm{C}$ featured a combined situation in which the three characters are moving as in Condition A (according to the scenario). In this combined situation, the prosocial character (Helper, Game-Player and Sharer) had a Caucasian face, and the antisocial (Hinderer, Game-breaker and Keeper) had a African or Asian one.

\section{Condition D (prosocial $x$ face)}

The three cartoons used in Condition $\mathrm{D}$ featured another combined situation in which the three characters are moving as in Condition A and $\mathrm{C}$ (according to the scenario). In this combined situation, the prosocial character (Helper, Game-Player and Sharer) had an African or Asian face, and the antisocial (Hinderer, Game-breaker and Keeper) had a Caucasian one.

In conditions $\mathrm{C}$ and $\mathrm{D}$, we combined prosociality with either own- or other-race face to assess if infants' preference for the prosocial character would change depending on variations in facial appearance.

\subsection{Procedure}

The experiment took place in a quiet room of our BabyLab [Insert Footnote1]. If the infants were comfortable with the situation, they were placed in a car seat in front of the screen and their parent sat next to them, with their backs to the screen, so that they could not see the cartoons. Otherwise, they sat on their parent's lap, and the parents were being requested to keep their eyes closed. Parents were instructed not to interact with their infant during the experiment, so as to avoid any interference.

Cartoons were displayed on a 24 -in. screen (1024 x 768 pixels), positioned approximatively $60 \mathrm{~cm}$ from the infant. Fixations were recorded with a Tobii X2-60 eye tracker (60-Hzdata sampling rate). An experimenter adjusted the position of the car seat during the calibration procedure. To start with, infants were shown cartoons of animated pets, to draw their attention to the screen. Once their eyes had been reliably detected, a noisy cartoon character sequentially popped up at five locations across the screen to calibrate the eye-tracker. If the first calibration failed owing to insufficient data, the same calibration procedure was repeated with another character and another sound. This could be repeated once, if need be, but if all three attempts failed, the experiment was abandoned. 
We implemented a within-participants design, in which infants were presented with all four cartoons and therefore tested for their visual preferences in the four conditions. The conditions $\mathrm{A}$ and $\mathrm{B}$ always preceded the conditions $\mathrm{C}$ and $\mathrm{D}$. Conditions $\mathrm{A}$ and $\mathrm{B}$ were showed in a counterbalanced order across infants (i.e., half the infants were presented condition $\mathrm{A}$, then condition $\mathrm{B}$; while the other half watched the two conditions in the reverse order). Conditions $\mathrm{C}$ and $\mathrm{D}$ were also showed in a counterbalanced order across infants (i.e., half of the infants were presented condition $\mathrm{C}$ first, then the condition $\mathrm{D}$; while the other half watched the two conditions in the reverse order). In conditions $\mathrm{A}, \mathrm{C}$ and $\mathrm{D}$, the side (i.e., spatial position regarding the infant) of the prosocial and antisocial characters, and the social nature of the first behaviour (prosocial or antisocial) were counterbalanced across infants. In conditions B, C and D, the other-race face factor (African/Asian) was used as a betweenparticipants factor, with half of the infants seeing cartoons featuring Caucasian versus African faces, and the other half seeing cartoons featuring Caucasian versus Asian faces.

\subsection{Data analysis}

For each cartoon, we selected four Areas Of Interest (AOIs) to analyse infants' fixations. The first two AOIs were the right and left characters in the scenario phase (prosocial vs. antisocial for cartoon 1; own-race vs. other-race face for cartoon 2; prosocial own-race face vs. antisocial other-race face for cartoon 3; prosocial other-race face vs. antisocial own-race for cartoon 4), and the last two AOIs were the same characters during the test phase. This permitted us to examine infants' visual preferences during the scenario (i.e., when the characters are moving) and at the test phase (i.e., when the characters were enlarged and static on the screen) [Insert Footnote2].

To analyse whether infants preferentially looked at one character, we computed an index of preference (IP) for scenario at each condition, which could vary from 0 to 1 , with 0.50 indicating that infants attended equally to both characters (preference at chance level). In each condition, the IP was calculated as the time spent looking at the one character (the prosocial, the own-race, the prosocial own-race, the prosocial other-race, in Condition A, B, C and $\mathrm{D}$, respectively) divided by the total amount of time spent looking at the two characters present in the cartoon. For example in condition A, an IP above 0.50 indicated that the infant focused longer on the prosocial character, and, by contrast, an IP below 0.50 indicated that the infant focused longer on the antisocial character.

We examine infants' preference for the prosocial versus antisocial and for the own-race versus the other-race character by performing two analyses of variance (ANOVA) with participants' age and scenario as between-participants variables in a first step with IP (Index of Preference) in the Condition A and in a second step with IP in the Condition B as the dependent variables. Last, we analyse the variations of IP between conditions A, C and D by running mixed ANOVA with conditions (A, C and D) as a within participant-variable, participants' age and scenario as between-participants variables and IP as the dependent variable Tukey post-hoc tests were applied when appropriate. The significance alpha level was fixed to 0.05 . Effects size were measured by partial Eta squared $\left(\eta^{2}\right)$, with small, medium and large effects defined as 0.01, 0.06 and 0.14 respectively (Cohen, 1988). All computations were performed using Statistica software release 7.1. 


\section{Results}

Preliminary analyses revealed no significant gender difference and no significant effect of race (i.e., no difference between sets competing Caucasian and African characters and sets competing Caucasian and Asian characters) on IP. Therefore, data were collapsed across gender and race in all further analyses reported below.

\subsection{Condition A-Prosocial}

To examine if infants' preference for the prosocial character varied according to their age and the scenario, we performed an analysis of variance (ANOVA) with participants' age and scenario as between-participants variables, and IP (index of preference) in the Condition A as the dependent variable. Results from the ANOVA indicated no significant main effect for age $(p>0.05)$ and for scenario $(p>0.05)$, but there was a significant interaction effect between the two variables with a medium size effect $\left(F(4,171)=4.84 ; p<0.001, \eta_{\mathrm{p}}^{2}=0.10\right)$ (cf. figure 2). The significant interaction was further analyzed using simple effects tests. More precisely, simple tests of age were run on each modality of scenario (Help, Play and Share), using one-way ANOVAs. Simple effects tests yielded a significant effect of participants' age in the Help $\left(\mathrm{F}(2,57)=5.923, \mathrm{p}<0.01, \mathrm{\eta}_{\mathrm{p}}^{2}=0.17\right)$ and in the Play $\left(\mathrm{F}(2,57)=4.045, \mathrm{p}<0.05, \mathrm{\eta}_{\mathrm{p}}^{2}\right.$ $=0.12$ ) scenario, with a big and medium size effects, respectively. No significant effect of participants' age were found in the Share scenario $(p>0.05)$. In the Help scenario, IP was found to significantly vary between 6 months and 12 months $(p<0.01)$. In the Play Scenario, IP was found to vary between 6 and 18 months $(p<0.01)$.

To further examine the preference for the prosocial characters and given that we had a directional prediction that infants' IP would be significantly above chance level we conducted one-tailed Student $t$-tests against mean (i.e. 0.5) to determine if the IP significantly differs from 0.5 , indicating a significant preference for one character. In the Help scenario, Student $t$ tests revealed a significant preference for the antisocial character at 6 months $(M=0.45, S D=$ $0.08 ; t=2.90, p<0.01)$ and for the prosocial character at 12 months $(M=0.54, S D=0.07 ; t=$ $2.33, p<0.05)$. In the Play scenario, Student $t$-tests revealed a significant preference for the prosocial character at 6 months $(M=0.54, S D=0.06 ; t=2.85, p<0.01)$. No preference was found in the Share scenario. 


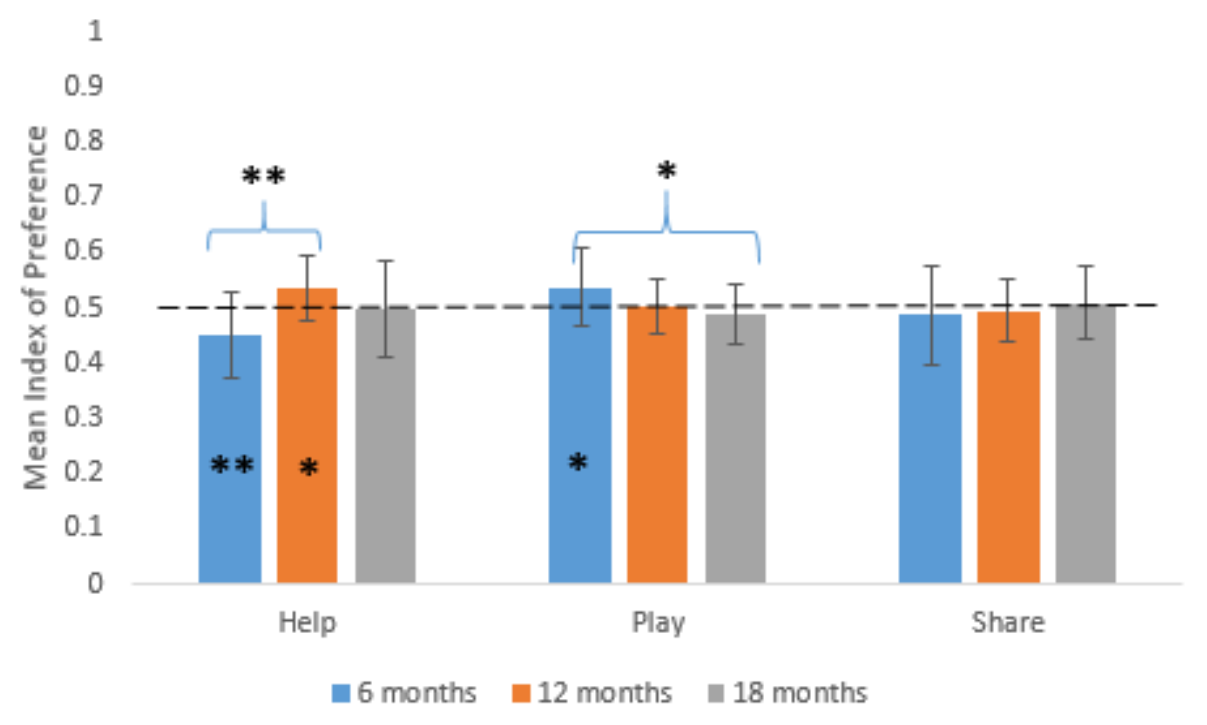

Figure 2. Mean Index of Preference in condition A obtained at 6, 12 and 18 months in each scenario (Help, Play, Share). Standards deviations are shown as error bars. An IP above 0.5

means reflects a preference for the prosocial character and an IP below 0.5 reflects a preference for the antisocial character. ${ }^{*} p<0.05, * * p<0.01$

\subsection{Condition B - Face}

To investigate infants' preference for one race, we performed an ANOVA with participant's age and scenario as between-participants variables, and IP in condition B as the dependent variable. Results from the ANOVA yielded a significant main effect of scenario with a small effect size $\left(F(2,171)=3.36 ; p<0.05, \eta_{\mathrm{p}}^{2}=0.04\right)$ (cf. table 2$)$. No other main or interaction effects were significant (all $p \mathrm{~s}>0.05$ ). Regarding the main effect of the scenario, IP in condition B was found to vary between the Help and the Play scenarios $(p<0.05)$.

To further examine the preference for the own- or other-race character and given that we had a directional prediction that infants' IP would be significantly above chance level we conducted one-tailed Student $t$-tests against mean (i.e. 0.5) to determine if the IP significantly differs from 0.5 . Student $t$-test revealed a significant preference for the other-race character in the Play $(t=3.89, p<0.001 ; M=0.38, S D=0.23)$ and in the Share scenario $(t=2.20, p<$ $0.05 ; M=0.46, S D=0.13)$.

Table 2

Mean and Standards deviations of Index of Preference obtained in Condition B in the three scenario (Help, Play, Share), with age (6, 12 and 18 months) collapsed. An IP above 0.5 means reflects a preference for the own-race and an IP below 0.5 reflects a preference for the other-race.

\begin{tabular}{lcc}
\hline Scenario & M & SD \\
\hline Help & 0.49 & 0.29 \\
Play & 0.38 & 0.23 \\
Share & 0.46 & 0.13 \\
\hline
\end{tabular}




\subsection{Conditions C and D- Prosocial $x$ Face}

To test the robustness of infants' preference for the prosocial character by investigating if the IP varied when the prosocial character displayed an own- or other-race face across the different age groups and scenarios, we run a mixed ANOVA with conditions (A, C and D) as a within subject-variable, participants' age and scenario as between-subjects variables and IP as the dependent variable. Results from the ANOVA indicated a significant main effect of the condition with a small effect size $\left(F(2,342)=8.50 ; p<0.001, \eta^{2}=0.05\right)$ (cf. table 3$)$ as well as a significant three-way interaction effect between conditions, age and scenario with a medium effect size $\left(F(8,342)=2.59 ; p<0.01, \eta_{\mathrm{p}}^{2}=0.06\right)$. No other main or interaction effects were significant (all $p \mathrm{~s}>0.05$ ). Regarding the main effect of the condition, IP was found to vary between Condition A and Condition $\mathrm{C}(p<0.01)$ and between Condition $\mathrm{C}$ and Condition D $(p<0.001)$. Two-tailed Student $t$-tests revealed a preference for the antisocial other-race character in Condition $\mathrm{C}(t=3.63, p<0.001 ; M=0.47, S D=0.11)$.

Table 3

Mean and Standards deviations of Index of Preference obtained in the three conditions $(A, C$, D), with age (6, 12 and 18 months) and scenario (Help, Play, Share) collapsed. An IP above 0.5 means reflects a preference for the prosocial, the own-race prosocial or the other-race prosocial characters (in Conditions $A, C$ and D respectively) and an IP below 0.5 reflects a preference for the antisocial, the other-race antisocial or the own-race antisocial character (in Conditions A, C and D respectively).

\begin{tabular}{lcc}
\hline Condition & $\mathrm{M}$ & $\mathrm{SD}$ \\
\hline Condition A & 0.50 & 0.07 \\
Condition C & 0.47 & 0.11 \\
Condition D & 0.51 & 0.009 \\
\hline
\end{tabular}

Follow-up simple effects tests were used to explore the exact nature of the interaction. More precisely, simple tests of the condition (A, C and D) were run within each modality of age (6, 12, 18 months) in each scenario (Help, Play, Share) considered separately, using one-way ANOVAs (cf. figure 3). In the Help scenario, simple effects tests yielded a significant effect of the condition with a big effect size at 6 months $\left(F(2,38)=3.68 ; p<0.05, \eta^{2}=0.16\right)$ and at 12 months $\left(F(2,38)=9.78 ; p<0.001, \eta_{\mathrm{p}}^{2}=0.34\right)$. At 6 months, IP was found to vary between Condition A and Condition $\mathrm{C}(p<0.05)$. Student $t$-tests revealed a significant preference for the antisocial character in Condition A $(M=0.45, S D=0.08 ; t=2.89, p<0.01)$. At 12 months, IP was found to vary between Condition A and Condition $\mathrm{C}(p<0.001)$ and between Condition $\mathrm{C}$ and Condition D $(p<0.01)$. Two-tailed Student $t$-tests revealed a significant preference for the prosocial character in Condition A $(t=2.339, p<0.05 ; M=0.54, S D=$ $0.07)$ and a preference for the antisocial other-race character in Condition $\mathrm{C}(t=3.017, p<$ $0.01 ; M=0.42, S D=0.12)$. In the Share scenario, we found a significant effect of the condition with a big effect size at 12 months $\left(F(2,38)=9.06 ; p<0.001, \eta_{\mathrm{p}}^{2}=0.32\right)$, IP was found to vary between Condition $\mathrm{C}$ and Condition $\mathrm{D}(p<0.001)$. Two-tailed Student $t$-tests 
revealed a preference at 12 months for the antisocial other-race character in Condition $\mathrm{C}(t=$ 3.14, $p<0.01 ; M=0.44, S D=0.08$ ). No effect was found in the Play Scenario.
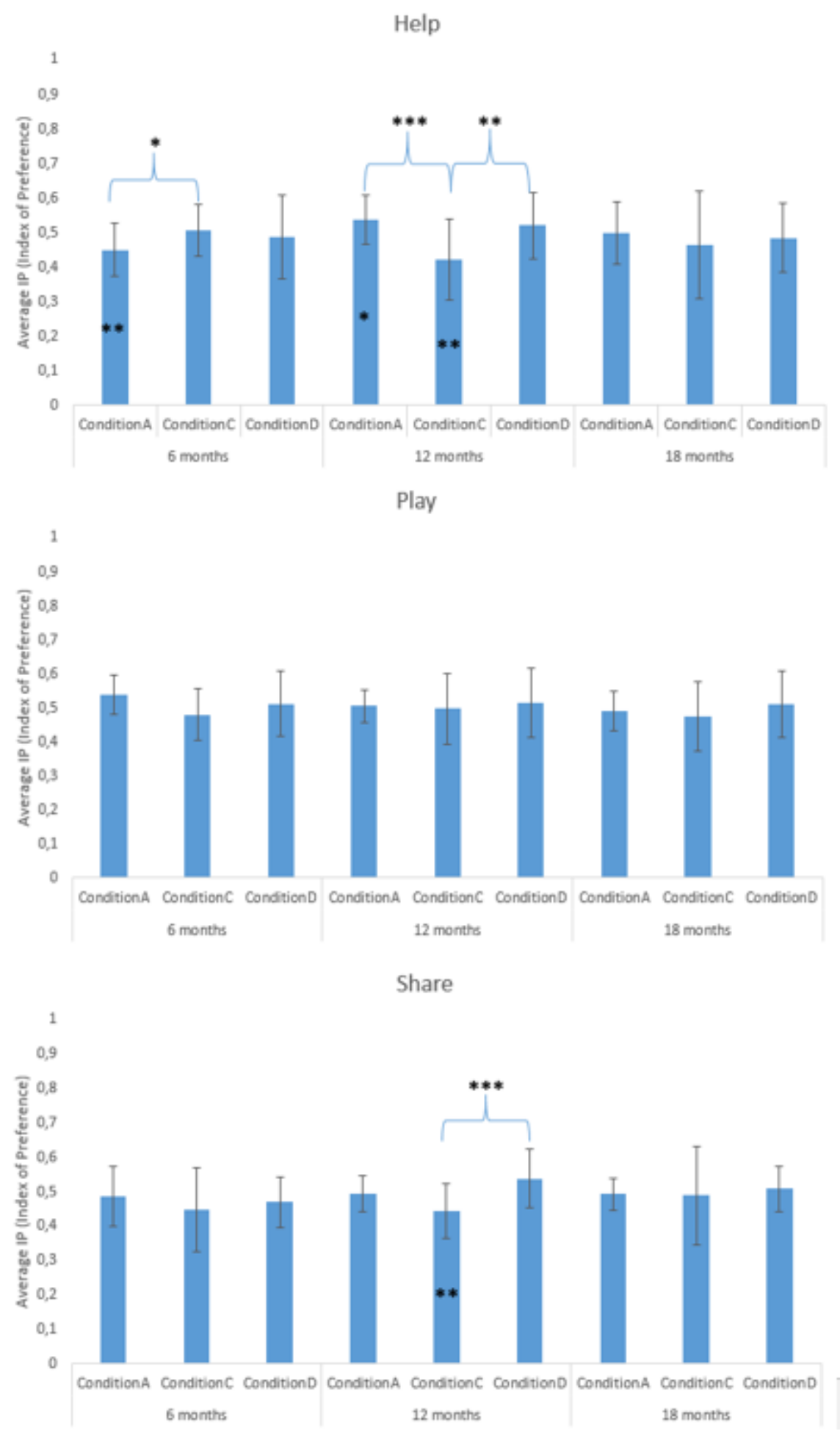

Figure 3. Mean Index of Preference obtained in the three conditions (A, C, D), according to age (6, 12 and 18 months) in each scenario (Help, Play, Share). Standards deviations are shown as error bars. An IP above 0.5 means reflects a preference for the prosocial, the ownrace prosocial or the other-race prosocial characters (in Conditions A, C and D respectively) and an IP below 0.5 reflects a preference for the antisocial, the other-race antisocial or the 
own-race antisocial character (in Conditions A, C and D respectively). $* p<0.05,{ }^{* *} p<$ $0.01, p<0.001$

\section{Conclusion}

This study was designed to address the following research questions: i) does the preference for the prosocial behaviour vary with age and depending on the social scenario?, and ii) do and how infants combine information about appearance and behaviour in their social evaluation? Our analyses yielded several results that are summarized and discussed below.

Regarding the possible variations of the preference for the prosocial behaviour depending on age and scenario (investigated in Condition A), our findings showed this preference is not present in a continuous and stable manner. At 6 months, infants demonstrate a preference for the prosocial agent in the Play scenario, whereas they display a preference for the antisocial one in the Help scenario. At 12 months, infants displayed a preference the prosocial agent only in the Help scenario. Infants aged 18 months did not display any preference in the three scenarios, possibly suggesting a developmental change. The preference for the antisocial behaviour in the Help scenario observed at 6 months conflicts with previous findings with the same age group and a similar scenario (Hamlin et al., 2007; Wallez et al., 2016). Even though this preference do not match our assumptions, infants' preference toward the antisocial agent demonstrates they have been sensitive to the prosocial and antisocial behaviours and display differentiated responses to. Why infants preferred the antisocial agent? One explanation could be that, even if they possess a moral sense that should make them prefer the prosocial agent, they may have been strongly surprised by the agent performing the antisocial agent so that they dedicated more time looking at him.

Second, we can observe that the scenarios are not processed equally as we reported more preferences in the Help scenario, less in the Play one, and none in the Share one. A possible explanation to these differences could be that the Play and Share scenarios were not sufficiently powerful to activate the concepts of 'prosociality' and 'antisociality'. It can be speculated that behaviours in the Play and Share scenarios did not enough convey their pro- or antisocial nature, especially when we compare with the Help scenario. Indeed, the behaviour of the Helper best represents the conceptual prototype of a prosocial behaviour: the agents' behaviour allows the central character to reach his objective. The social nature of the behaviours showed in the Play and Share scenarios, however, may have been far more difficult to be perceived by our young participants. In the Play scenario featuring a ball game, to perceive the Game-player and the Game-breaker as pro- and anti-social agents involves the understanding of that the ball game is a rule-based and social game, that a game-breaker violated the rules. The infants that participated may just have perceived the agents as preferring to play alone or with someone else. In the same vein, in the Share scenario, infants might have perceived the Sharer and the Keeper as expressing preference for social games or for selfish games. By the way, considering that children begin to voluntarily share with others in the second year of life (Brownell, Svetlova \& Nichols, 2009), we can assume that young infants aged between 6 and 18 months would prefer to keep their toy for themselves and would not perceive a keeper as antisocial. These results let open the broad debate of what are prosocial and antisocial behaviours. 
Congruent with previous findings with drawing faces (Holvoet et al., submitted), we found that infants prefer an agent featuring an other-race face in the face condition. This preference was found in the Play and Share scenarios, and was stronger in the Play one. Why this preference did not emerge in the Help Scenario, and why in a minor extent in the Share scenario compared to the Play one? One explanation could be found in some perceptual aspects of the animated cartoons. For example in the Play scenario, the background is slightly more complex as it featured two trees on each boundary side of the screen which may have drawn infants' visual attention to the boundary sides of the screen, where the agents also were, so that infants may have more spontaneously processed their appearance/face. However, in the Share scenario, agents' spatial position were very close to one another with a central position, which may have lower infants' processing of agents' appearance. Last, in the Help scenario, the movement of the central character, jumping continuously toward the toy placed above him, may have drawn infants' attention on it so that they did not process agents' appearance. To sum-up, when the perceptual aspects were appropriate to draw infants' attention toward agents' appearance/face, and in line with our prediction we found a preference for the agent featuring an other-race face. However, our mixed results invite us to be particularly prudent when designing material used with young infants.

The last aim of this study was to investigate whether and how infants incorporate information about behaviours and information about appearance in their social evaluation by examining how they react to the combined conditions. Our results showed infants aged 12 months processed differently these combined conditions in the Help and Share scenarios. Indeed, and equally in the two scenarios, we observed two different reactions according to the combined condition: a preference for the antisocial other-race agent in condition $\mathrm{C}$ and no preference in condition $\mathrm{D}$. This pattern partially corroborates one of our hypothesis, which was the following: 'if infants display a preference for face over behaviour, they should show a visual preference for the other-race antisocial agent in condition $\mathrm{C}$, and for the other-race prosocial agent in condition D'. However, we found the preference in condition $\mathrm{C}$ whereas no preference in condition $\mathrm{D}$. Therefore, we cannot strongly conclude that infants prioritize appearance over behaviour. Another interpretation that could be read from the results is that, as previously highlighted, our scenarios were not sufficiently powerful to activate the concepts of 'prosociality' and 'antisociality'. Thus, if infants did not react differently to these behaviours, we could assume infants may have only reacted when they saw something surprising or attention-focusing. Based on our results in face condition, we know that infants were attracted by agents featuring an other-race face. Their attention focused on this agent, we can assume that the infants have consequently payed more attention to his behaviour, which is surprising in condition $\mathrm{C}$ through its antisocial nature. Therefore, it could be the combination of these two surprising elements that may have sufficiently driven infants' attention toward this agent so that we found a preference. Thus, even if this interpretation gives partially sense to the hypothesis that infants prioritize face over behaviour, it also highlights that only a combination of two surprising elements allows to reach a threshold at which the scenario becomes enough worthy of interest to generate preferences. A last point that could be noted is that infants might have perceived the agents in the combined conditions as acting inconsistently, and it has recently be shown that infants did not express any preference when 
exposed to agents performing variably prosocial and antisocial behaviours (Steckler, Woo and Hamlin, 2017).

In summary, our study provide the following conclusions. First, the preference for the prosocial behaviour was not reported in a stable manner. This instability could be due on the one hand to developmental changes, and on the other hand to the behaviours featured in the Play and Share scenarios that were possibly not sufficiently powerful to activate the concepts of 'prosociality' and 'antisociality'. Second, consistent with previous findings, we observe a preference for the agents featuring an other-race face. Third, when infants have to simultaneously incorporate information about appearance and behaviour, our results partly validate the hypothesis that infants would prioritize information about appearance. However, the results also suggest that it could have been the combination of two surprising and/or attention-focusing elements that make the infants display a preference. Overall our results lead us to draw the following proposal: infants seem to prefer the prosocial agent, however, what are the specific parameters needed to make infants display this preference? We can ask if our animated cartoons were sufficiently attractive to make the infants relevantly processed the interactions, especially when we compare with the kind of material used in previous studies (for example, plush toys displaying attractive voice patterns in Hamlin \& Wynn, 2011, or fun characters with large head and smallish bodies in Scola et al., 2015) or even with the animated cartoons infants are used see on T.V that are highly dynamic. In the current study, our aim was to show to infants a material which presents optimum control: our animated cartoons were designed so that the color of the agents were equally attractive, the behaviours were displayed at the same velocity, the videos have exactly the same duration. However, in our pursuit of better control on these elements, our cartoons may have lost in attractiveness, especially with our older participants. More research that reach a better balance between attractiveness and control is needed to improve this material to further explore infants' preference for prosocial behaviours.

\section{References}

Brownell, C. a, Svetlova, M., \& Nichols, S. (2009). To share or not to share: When do toddlers respond to another's needs? Infancy: The Official Journal of the International Society on Infant Studies, 14(1), 117-130. https://doi.org/10.1080/15250000802569868

Buon, M., Jacob, P., Margules, S., Brunet, I., Dutat, M., Cabrol, D., \& Dupoux, E. (2014). Friend or foe? Early social evaluation of human interactions. PLOS ONE, 9(2), e88612. http://doi.org/10.1371/journal.pone.0088612

Burns, M. P., \& Sommerville, J. A. (2014). "I pick you”: The impact of fairness and race on infants' selection of social partners. Frontiers in Psychology, 5(FEB), 1-10. http://doi.org/10.3389/fpsyg.2014.00093

Cogsdill, E. J., Todorov, A. T., Spelke, E. S., \& Banaji, M. R. (2014). Inferring Character From Faces: A Developmental Study. Psychological Science, 25(5), 1132-1139. https://doi.org/10.1177/0956797614523297 
Cohen, J. (1988). Statistical power analysis for the behavioral sciences. Hillsdale, NJ: Erlbaum.

Cowell, J. M., \& Decety, J. (2015). Precursors to morality in development as a complex interplay between neural, socioenvironmental, and behavioral facets. Proceedings of the National Academy of Sciences, 112(41), 201508832. http://doi.org/10.1073/pnas.1508832112

Decety, J., \& Cowell, J. M. (2017). Interpersonal harm aversion as a necessary foundation for morality: A developmental neuroscience perspective. Development and Psychopathology, 1-12. https://doi.org/10.1017/S0954579417000530

Fassbender, I., Teubert, M., \& Lohaus, A. (2016). The development of preferences for ownrace versus other-race faces in 3-, 6- and 9-month-old Caucasian infants. European Journal of Developmental Psychology, 13(1), 152-165. http://doi.org/10.1080/17405629.2015.1073585

Geraci, A., \& Surian, L. (2011). The developmental roots of fairness: infants' reactions to equal and unequal distributions of resources. Developmental Science, 14(5), 1012-1020. http://doi.org/10.1111/j.1467-7687.2011.01048.x

Hamlin, J. K. (2013). Failed attempts to help and harm: Intention versus outcome in preverbal infants' social evaluations. Cognition, 128(3), 451-474. http://doi.org/10.1016/j.cognition.2013.04.004

Hamlin, J. K. (2014). The case for social evaluation in preverbal infants : Gazing toward one's goal drives infants' preferences for helpers over hinderers in the hill paradigm. Frontiers in Psychology, 5(1563), 1-9. http://doi.org/10.3389/fpsyg.2014.01563

Hamlin, J. K., \& Wynn, K. (2011). Young infants prefer prosocial to antisocial others. Cognitive Development, 26(1), 30-39. http://doi.org/10.1016/j.cogdev.2010.09.001

Hamlin, J. K., Wynn, K., \& Bloom, P. (2007). Social evaluation by preverbal infants. Nature, 450(7169), 557-559. http://doi.org/10.1038/nature06288

Hamlin, J. K., Wynn, K., \& Bloom, P. (2010). Three-month-olds show a negativity bias in their social evaluations. Developmental Science, 13, 923-929. http://doi.org/10.1111/j.1467-7687.2010.00951.x

Hamlin, J. K., Wynn, K., Bloom, P., \& Mahajan, N. (2011). How infants and toddlers react to antisocial others. Proceedings of the National Academy of Sciences, 108(50), 19931-6. http://doi.org/10.1073/pnas.1110306108

Hamlin, J. K., Ullman, T., Tenenbaum, J., Goodman, N., \& Baker, C. (2013). The mentalistic basis of core social cognition: Experiments in preverbal infants and a computational model. Developmental Science, 16, 209-226. http://doi.org/10.1111/desc.12017

Holvoet, C., Scola, C., Arciszewski, T., \& Picard, D. (submitted). Infant's perception of faces: are cartoons of face perceived differently from photographs? Perception. 
Holvoet, C., Scola, C., Arciszewski, T., \& Picard, D. (2016). Infants' preference for prosocial behaviors: A literature review. Infant Behavior and Development.

http://doi.org/10.1016/j.infbeh.2016.10.008

Houston-Price, C., \& Nakai, S. (2004). Distinguishing novelty and familiarity effects in infant preference procedures. Infant Child Development, 13, 341-348.

http://doi.org/10.1002/icd364

Liu, S., Xiao, W. S., Xiao, N. G., Quinn, P. C., Chen, H., Pascalis, O., \& Lee, K. (2015).

Development of visual preference for own- versus other-race faces. Developmental Psychology, 51(4), 500-511. http://doi.org/10.1037/a0038835

Oakes, L. M. (2012). Advances in eye tracking in infancy research. Infancy, 17(1), 1-8. http://doi.org/10.111/j.1532-7078.2011.00101.x

Olivola, C. Y., Funk, F., \& Todorov, A. (2014). Social attributions from faces bias human choices. Trends in Cognitive Sciences, 18(11), 566-70. https://doi.org/10.1016/j.tics.2014.09.007

Quinn, P. C., Yahr, J., Kuhn, A., Slater, A. M., \& Pascalis, O. (2002). Representation of the gender of human faces by infants: A preference for female. Perception, 31, 1109-1121. http://doi.org/10.1068/p3331

Salvadori, E., Blazsekova, T., Volein, A., Karap, Z., Tatone, D., Mascaro, O., \& Csibra, G. (2015). Probing the Strength of Infants' Preference for Helpers over Hinderers: Two Replication Attempts of Hamlin and Wynn (2011). PloS One, 10(11), e0140570. http://doi.org/10.1371/journal.pone.0140570

Scola, C., Holvoet, C., Arciszewski, T., \& Picard, D. (2015). Further Evidence for Infants' Preference for Prosocial Over Antisocial Behaviors. Infancy, 20(6), 684-692. http://doi.org/10.1111/infa.12095

Steckler, C. M., Woo, B. M., \& Hamlin, J. K. (2017). The limits of early social evaluation: 9month-olds fail to generate social evaluations of individuals who behave inconsistently. Cognition.

https://doi.org/10.1016/j.cognition.2017.03.018

Stewart, L. H., Ajina, S., Getov, S., Bahrami, B., Todorov, A., \& Rees, G. (2012). Unconscious evaluation of faces on social dimensions. Journal of Experimental Psychology: General, 141(4), 715-727. http://doi.org/10.1037/a0027950

Todorov, A., Pakrashi, M., \& Oosterhof, N. N. (2009). Evaluating Faces on Trustworthiness After Minimal Time Exposure. Social Cognition, 27(6), 813-833.

https://doi.org/10.1521/soco.2009.27.6.813 
Wallez, C., Scola, C., Holvoet, C., \& Meunier, H. (2016). L'évaluation des comportements pro versus antisociaux chez le jeune enfant : apport de l'oculométrie. Approche Neuropsychologique des Apprentissages chez l'Enfant, 142, 001-007.

Footnote:

1. The experiments were conducted in our BabyLab of the Maison de la Recherche, at Aix Marseille University, France.

2. Infants' visual preference at test phase were recorded but we made the choice to focus on visual preferences during scenario.

Supplementary Information

\section{$\underline{\text { Help scenario }}$}

Each cartoon showed three human-like characters on a simple background including at the middle of the screen a toy as if it was hanging from the ceiling. The toy looks like a rattle with four branches, with a brightly coloured round at the end of each branch. The central character repeatedly jumps with his head up (his eyes looking for the toy) and his arms raised toward the toy placed above him. At the beginning, the two other characters stay on the right and on the left side of the central character and look at him. The "Helper" behaves in a prosocial way and goes toward the central character, raises him so as he could touch the toy for a few seconds; the "Hinderer" goes toward the central character and prevents him from jumping three times.

\section{$\underline{\text { Play scenario }}$}

The simple background includes two trees, one on each boundary side of the screen. The central character holds a ball whereas the two moving characters do not have one. The central character played with a ball and then threw it to alternatively to each character (staying on his right and on his left side) to play with them. The "Game-player" gave the ball back so that the game could continue; the "Game-breaker" kept the ball and kicked the ball in the tree next to him.

\section{$\underline{\text { Share scenario }}$}

The two moving characters on the left and right sides each hold a toy, whereas the central character has not. The toy looks like a rattle with four branches, with a brightly coloured round at the end of each branch. At the beginning, the two other characters stay on the right and on the left side of the central character. The central character repeatedly extends his arms toward one character on his left or right side as if he tries to reach the toy hold by the moving character. The "Sharer" cuts his toy in two pieces and gives one to the central character, who plays with it for a few seconds before giving it back to the moving character. The "Keeper" turns his back so that the he puts the toy out of the reach of the central character and keeps it. 